\title{
A IMPORTÂNCIA DA LEITURA NA EDUCAÇÃO INFANTIL
}

\author{
Girlane Paula Domingos ${ }^{1}$ \\ Leda Elaine Silveira Hortêncio Mesquita ${ }^{2}$ \\ Maria Zildineth Sergio ${ }^{3}$ \\ Patrícia Abigail Borges Amorim ${ }^{4}$ \\ Tânia Rosa Machado 5
}

RESUMO: Este Artigo tem como objetivo mostrar a importância da leitura na educação infantil e os incentivos que os educadores devem propor às crianças desde os primeiros anos de vida no ambiente escolar para promover a formação de futuros leitores cidadãos. $\mathrm{Na}$ educação infantil, as crianças precisam estimular sua imaginação, linguagem e fantasia por meio de livros. A leitura é inspirada pela criatividade e imaginação e os professores que usam livros infantis proporcionam às crianças o desenvolvimento em todos os aspectos: emocional, social, sensorial, cognitivo e crítico. Eles usam gestos, expressões e entonações para capturar todos os dias para construir conhecimentos diversos.

Palavras-Chave: Educação Infantil. Literatura Infantil Livros. Leitura.

ABSTRACT: This article aims to show the importance of reading in early childhood education and the incentives that educators should propose to children from the first years of life in the school environment to promote the formation of future citizen readers. In early childhood education, children need to stimulate their imagination, language and fantasy through books. Reading is inspired by creativity and imagination and teachers who use children's books provide children with development in all aspects: emotional, social, sensory, cognitive and critical. They use gestures, expressions and intonations to capture everyday to build diverse knowledge.

Keywords: Early Childhood Education. Children's Literature. Books. Reading.

\footnotetext{
I Graduada em Pedagogia pela UFMT - Universidade Federal de Mato Grosso - Especialista em Alfabetização e Letramento pela UNIC- Universidade de Cuiabá.

${ }^{2}$ Graduada em Pedagogia pelas Faculdades Integradas de Ariquemes, Graduada em Letras com ênfase em Português/Inglês pelo UNIVAG - Centro Universitário, Especialista em Educação Infantil e Alfabetização pela FACIB - Faculdades Impactos Brasil e Especialista em Alfabetização e Letramento pela FACIB Faculdades Impactos Brasil.

${ }^{3}$ Graduada em Pedagogia pela Faculdade Invest de Ciências e Tecnologia, Graduada em Biologia pela UNIC - Universidade de Cuiabá, Especialista em Educação Infantil e Séries Iniciais pela Faculdade Invest de Ciências e Tecnologia.

${ }^{4}$ Graduada em Pedagogia pela Faculdade IDEAL, Graduada em Biologia pelo UNIVAG - Centro Universitário, Especialista em Mídias Digitais para a Educação pela UFMT - Universidade Federal de Mato Grosso.

${ }^{5}$ Graduada em Pedagogia pela UFMT Universidade Federal de Mato Grosso, Graduada em Letras com ênfase em Libras pela UFMT - Universidade Federal de Mato Grosso, Especialista em Educação Infantil pela Faculdade Invest de Ciências e Tecnologia.
} 


\section{INTRODUÇÃO}

O reconhecimento da importância da leitura na educação infantil passa pela estimulação da formação de hábitos de leitura na idade em que todos os hábitos são formados, ou seja, a infância. A literatura infantil é um caminho que leva cada criança a estimular a sua imaginação, emoções e sentimentos de forma prazerosa e significativa. $O$ hábito pela leitura na infância auxilia a despertar na criança o senso crítico, sendo de suma importância para elas como indivíduo no processo de formação e traz auxilio para o aprendizado (NÓBREGA \& MANGIERA, 2021).

Este artigo apresenta de forma breve a literatura infantil, destacando os conceitos de linguagem e leitura, enfatizar a importância de ouvir histórias e da exposição de livros na primeira infância e mostrar algumas estratégias para cultivar hábitos de leitura.

A aquisição da leitura se torna cada vez mais condição indispensável para a plena participação social, devido ao atual contexto, imerso em inúmeras informações e conhecimentos (FORTESKI et al 20II).

\section{DESENVOLVIMENTO \\ 2.I Conceitos de Leitura}

Para Martins (2003), a leitura é uma atividade básica na formação cultural do ser humano, atende a diversas finalidades, entre elas o senso crítico aguçado e uma maior percepção das diversas leituras intelectuais e do mundo, permitindo assim analisar toda e qualquer leitura. Destaca que a leitura não é apenas das palavras, mas a da leitura de mundo, sendo necessária a observação do que está em nossa volta, mostra o quanto pode ser amplo o sentido de leitura, não se restringe à palavra escrita, mas um infinito de possibilidades, tais como imagens, sons, fotografias, situações e tantas outras leituras e interpretações do mundo que nos possibilita ler antes do contato com a escola. O simples fato de uma criança folhear um livro ou revista, observar suas figuras, sentir a textura das folhas, selecionar exemplares por tamanho ou por quaisquer itens que chamem sua atenção indica interesse pelo universo da leitura, que pode e deve ser incentivado pelos pais desde pequenos, lendo para eles, permitindo o manuseio de livros, revistas, jornais e principalmente mostrando que eles gostam de ler, este com certeza é o maior incentivo à leitura que uma criança pode obter. O livro mostra também que a leitura está ligada às 
sensações, emoções e a razão. Exemplifica que quando algo desperta reações em nosso corpo e nos faz ter emoções boas ou ruins conseguimos guardá-lo conosco, vindo à tona sempre que nos deparamos com algo relacionado a ele.

Esta mesmo autora entende que a interpretação do que se lê é fundamental a história de vida do leitor. A leitura ao jeito de cada leitor: Fundamental mesmo é a continuidade da leitura, o interesse em realizá-la. Incentiva o ato de reler por acreditar que a releitura permite novas direções para esclarecer dúvidas, também acredita que não devemos ter receio de trazer para a leitura vivências anteriores” (MARTINS, 2003).

O processo de ler é complexo, assim como em outras tarefas cognitivas, resolver problemas, trazer à mente uma informação necessária, aplicar algum conhecimento a uma situação nova, o engajamento de muitos fatores (percepção, atenção, memória) é essencial se querem fazer sentido do texto (KLEIMAN, 200I).

Segundo Kleiman (2001), o conceito de leitura é muito amplo, pois envolve uma infinidade de possibilidades de respostas. Para entender o conceito de leitura, não basta procurar no dicionário o significado da palavra, pois ler envolve uma série de práticas e experiências, suas necessidades de leitura, seus gestos, sua habilidade, as maneiras de ler, instrumentos, apropriação e processos de interpretação, enfim, ler é considerar aquilo que envolve o leitor.

Magnani (1989) afirma que a leitura como ato de decodificar sinais gráficos, ou seja, um ato mecânico, pode se tornar uma prática sem vida e sem alma, mas se, em vez disso, considerá-la como as experiências e vivências, a leitura se tornará uma prática muito mais ampla e viva, na qual o pulsar das informações baterá no mesmo ritmo das emoções.

Aprender a ler significa também aprender a ler o mundo, dar sentido a ele e a si próprio, o que, mal ou bem, faz-se mesmo sem ser ensinado. A função do educador não seria precisamente a de ensinar a ler, mas a de criar condições para o educando realizar a sua própria aprendizagem, conforme seus próprios interesses, necessidades, fantasias, segundo as dúvidas e exigências que a realidade lhe apresenta. Assim, criar condições de leitura não implica apenas alfabetizar ou propiciar acesso aos livros. Trata-se, antes, de dialogar com o leitor sobre a sua leitura, isto é, sobre o sentido que ele dá, a algo escrito, um quadro, uma paisagem, a sons, imagens, coisas, ideias, situações reais ou imaginárias (MARTINS, 1994). 
O livro leva a criança a desenvolver a criatividade, a sensibilidade, a sociabilidade, o senso crítico, a imaginação criadora, e algo fundamental, o livro leva a criança a aprender

o português. É lendo que se aprende a ler, a escrever e interpretar. É por meio do texto literário (poesia ou prosa) que ela vai desenvolver o plano das ideias e entender a gramática, suporte técnico da linguagem. Estudá-la, desconhecendo as estruturas poéticoliterárias da leitura, é como aprender a ler, escrever e interpretar, e não aprender a pensar (PRADO, 1996)

\subsection{Literatura infantil}

Para Camargo \& Silva (2020) a Literatura Infantil possibilita às crianças novas experiências com a linguagem e com os sentidos, ou seja, proporciona um melhor desenvolvimento linguístico, cognitivo, emocional e sociocultural. Assim, o professor deve oportunizar a leitura desde o início da escolarização, pois isso poderá torna-los futuros leitores, capazes de interpretar o mundo de uma maneira mais consciente e crítica.

Generoso (2014) entende que a literatura infantil deve fazer parte do cotidiano da

sala de aula, sendo que essa perspectiva é sugerida na medida em que se tem a Literatura Infantil possibilita uma aprendizagem mais significativa através do desenvolvimento da imaginação promovido pelos gêneros textuais literários.

Ao tratar do tema "Literatura Infantil na Educação Infantil”, o educador pode lançar mão de diversas práticas pedagógicas juntamente com a criança, despertando na mesma a valor pela leitura.

Para Coelho (200o) a leitura inteligente, aquela que esclarece e enriquece o espírito depende não só da aquisição do mecanismo da leitura, mas de toda uma educação preparatória. Esta educação, esta pré-leitura é precisamente a razão de ser alguns de nossos álbuns de figuras e de atividades.

A leitura infantil, poderá ser trabalhada através de imagens e figuras ilustrativas que se compõem no espaço lúdico em sala de aula.

Coelho (2000) diz que a leitura total é a conquista do meio instrumental de compreensão, de tomada de posse da informação, em sentido amplo. Isso supõe uma dinâmica interrogativa diante dos acontecimentos do texto e da imagem. O livro deve responder a todos as curiosidades. 
No entanto, por conta de práticas tradicionais ainda existentes na escola, ocorre o desestímulo na prática da leitura e, com ele, este processo de compreensão da realidade se torna mais lento e limitado. Logo, a escola precisa deixar de trabalhar a leitura de maneira mecânica e desestimulante. Segundo Sorrenti (1995, p. 22), "a leitura precisa ser vista com os olhos do prazer, respondendo as indagações e as necessidades de cada um".

Diante deste contexto, não basta a escola alfabetizar, é preciso transformar a criança em um bom leitor (JARDIM, 1994). Assim sendo, cabe ao educador estimular a criança a viver a magia da leitura. É ele quem vai escolher os livros adequados e interessantes, vivenciando-o com a turma como uma arte, como também proporcionar às crianças momentos de seleção e troca de livros (ALBUQUERQUE, 2013).

\subsection{A importância das histórias na educação infantil}

O professor precisa levar em consideração as preferências de seus alunos. Conforme Alves apud Garcia (2010, p. 4) “O lugar da literatura não é a cabeça: é o coração". Desse modo, a contação de histórias é um excelente recurso, que o professor pode e deve usar para desenvolver, a partir da literatura infantil a leitura, especialmente o gosto, o prazer de pegar um livro e ler com satisfação e alegria.

O professor pode utilizar de diversas estratégias para desenvolver junto aos alunos a leitura e a escrita. O texto literário é um instrumento que facilita essa prática, criando diversas oportunidades de diálogo, compreensão acerca do que as crianças sentem e como compreendem determinada leitura. $\mathrm{Na}$ "hora do conto", essa questão pode ser bastante desenvolvida através do levantamento de hipóteses, expressão dos sentimentos e emoções das crianças através de desenhos, do reconto da história de forma escrita, representação em forma de dramatização e outros artifícios. Trabalhar com as diversas linguagens da criança torna-se um recurso essencial na educação infantil em relação ao aprender a ler e a escrever (RODRIGUES, 20II).

Conforme Ferreira (2007) toda criança gosta de ouvir história, associando a realidade à fantasia e geralmente se identificando com algum personagem. A criança, portanto, precisa ser estimulada para que possa desenvolver o gosto pela leitura, e existe diversos modos para isso ocorra com uma mesma história, o conto original, o reconto, desenhos, dramatização, leva a interação com a história, vivenciando o que está sendo contado, a imaginação da criança fluirá. Além de ser na Educação Infantil que a criança 
vive o imaginário, o lúdico, o faz-de-conta fica mais evidenciado. Assim, a leitura das histórias na Educação Infantil faz-se importante na formação das crianças e através deles podem formar-se e informar-se acerca da vida e dos ambientes em sua volta.

É preciso que mais atividades com a experiência da arte de contar histórias sejam realizadas nas escolas a fim de semear sonhos, esperanças, ensinamentos. Isso porque essa arte alimenta a poesia, a imaginação e inspira o ouvinte a ver com outros olhos, auxiliando-o a crescer, ampliar alternativas, resolver dilemas, escolher ser autônomo e nutrir essência com a sabedoria (FERRERIA \& OLIVEIRA, 2020).

A literatura infantil, embora seja uma vertente da literatura geral que prima, na maioria das vezes, pela escrita voltada à determinada faixa etária, tendo obras com conteúdos voltados ao imaginário humano, auxiliando na compreensão e a resolução de conflitos internos de cada indivíduo de modo particular (SILVA, 2009).

Para Coelho (2000, p. 120): “[...] a escola é hoje o es paço privilegiado em que deverão ser lançadas as bases para a formação do indivíduo. E, nesse espaço, privilegiamos os estudos literários, pois, de maneira abrangente do que quaisquer outros, eles estimulam o exercício da mente, a percepção do real em suas múltiplas significações, a consciência do eu em relação ao outro, a leitura do mundo em seus vários níveis e, principalmente dinamizam o estudo e conhecimento da língua, da expressão verbal significativa e consciente, condição sine qua non para a plena realidade do ser”.

Diversas fontes de aprendizagens podem ser obtidas através das histórias, colaborando para o incentivo à leitura e escrita até a noção de valores e sentimentos que são vividos pelo ser humano, manifestados através da escuta de uma história. Esses valores permitem uma reflexão da criança acerca do convívio em sociedade. (FRANCISCO, 2009).

Assim sendo, o docente precisa criar momentos de leitura com objetivo estimular a formação de leitores e escritores buscando interação e ludicidade na literatura infantil (FRANCISCO, 2015).

\subsection{Importância do ato de ler}

Paulo Freire (2017) em sua obra diz que a leitura da palavra é sempre precedida da leitura do mundo. $\mathrm{O}$ ato de aprender a ler, a escrever, alfabetizar-se é, antes de mais nada, 
aprender a ler o mundo, ter a compreensão do seu contexto, não uma manipulação mecânica de palavras, mas através de uma relação dinâmica vinculando linguagem e realidade. A aprendizagem da leitura e a alfabetização são atos de educação, e este autor considera educação é um ato essencialmente político.

Desse modo Paulo Freire (2017) reafirma a importância de que educadores e educandos tenham um posicionamento crítico ao vivenciarem a educação, superando as posturas ingênuas ou "astutas", que nega de vez a pretensa neutralidade da educação.

A alfabetização é a criação ou a montagem da expressão escrita da expressão oral. Esta montagem não pode ser feita pelo educador para ou sobre o alfabetizando. Aí tem ele um momento de sua tarefa criadora (FREIRE, 2017).

\subsection{Importância da leitura na educação infantil}

Para Landim \& Flôres (2018) [...] no início e durante o processo de alfabetização, para que resultados negativos como os apontados pela pesquisadora e pelas avaliações externas não continuem se repetindo. Em decorrência, faz-se necessário compreender o processo de aprendizagem da leitura $e$ as intervenções que podem ser feitas pelos professores e também pelos pais, que podem contribuir para que as crianças tenham sucesso nas tarefas relacionadas à leitura.

Essas mesmas autoras destacam, a importância da relação da criança no seio familiar ser rica em experiências que contemplem a leitura, o manuseio de livros, a contação de histórias, dentre outras atividades que a família possa desenvolver com ela e que promovam o desenvolvimento das competências fundamentais para o aprendizado da leitura.

$\mathrm{Na}$ educação infantil, enfatiza-se a importância das atividades orais que permitam à criança brincar com a língua, como as cantigas, as parlendas, os travalínguas, as brincadeiras de escuta, de identificação de sons, os jogos de faz de conta, as representações teatrais e atividades mais elaboradas, que permitam a identificação de rimas, a criação de novas rimas, de mudar partes da palavra, de encontrar palavras escondidas, entre outras, são cruciais. Se este trabalho de percepção da língua oral e também visual (olhar para o que está escrito), bem como o contato com a leitura e práticas de contação de histórias e manuseio de livros tiver acontecido antes de a criança ingressar no primeiro ano e se o trabalho pedagógico for eficiente, ela levará alguns meses apenas para se alfabetizar. 
Certamente, não precisará de três anos para completar o ciclo de alfabetização (LANDIM \& FLÔRES, 2018).

Atualmente, um dos grandes desafios enfrentados na área da educação infantil é o de conseguir adaptar à sala de aula com valores e prática pedagógica que atenda às necessidades das crianças que já estão vivendo o processo de aquisição de leitura e escrita.

É muito importante reforçar que o professor deve selecionar diferentes tipos de textos, literários ou não, que projetem a vida contemporânea do local onde os alunos estão inseridos, bem como de outros lugares e tempos, os diversos pontos de vistas, estimulando discussões, reflexões e confrontos entre os alunos.

O desenvolvimento intelectual da educação infantil representa um fator políticosocial básico para o alcance do progresso de aspiração de toda a sociedade. Assim, a construção do conhecimento, segundo entendimento de alguns autores como elemento principal, se efetivará pelo hábito da leitura, uma vez inserida e enfatizada no contexto escolar. Afinal, é principalmente através da leitura que os alunos poderão encontrar respostas aos seus questionamentos, dúvidas e indagações, mormente no que concerne aos caminhos por onde permeiam na construção do seu conhecimento, e não em uma metodologia tradicional.

Assim, ler é produzir sentido, é fazer o exercício pleno do letramento, é estar contextualizado no texto, interpretando-o e atribuindo-lhe algum significado. Portanto torna-se importante a criação de situações para que o exercício da leitura e escrita produzam reações, interações, construção da subjetividade e conhecimento, não servindo apenas como uma atividade meramente de cópia ou de decodificação dos sinais gráficos, cujo processo aliena o aluno do contexto em que está inserido (NUNES et al. 2020).

Para Goulemot (1996, p. 107) "leitura é sempre produção de sentido", sendo que cada pessoa atribui um sentido específico para a leitura realizada, ampliando-se a significação do ato de ler quando se toma como referência diversas possibilidades de leitura, como em obras de arte, imagens, fotografias, livro-imagem, expressões teatrais, sinais, cores, melodias, por exemplo. A leitura vai além do olhar para algo, adentra no imaginário transformando-se em ato cognitivo, potencializando a compreensão, da sensibilidade e da emoção. 
O documento oficial Referencial Curricular Nacional para a Educação Infantil, RCNEI publicado em 1998, apresenta orientações aos professores, descreve a leitura como: “[...] um processo em que o leitor realiza um trabalho ativo de construção do significado do texto, apoiando-se em diferentes estratégias, como seu conhecimento sobre o assunto, sobre o autor e de tudo o que sabe sobre a linguagem escrita e o gênero em questão". (BRASIL, 1998, p. 133)

A Base Nacional Curricular Comum (BRASIL, 2017) descreve que a criança desponta curiosidade com relação à cultura escrita, em diferentes atividades, como ao ouvir e acompanhar a leitura de textos, ao observar os muitos textos que circulam no contexto familiar, comunitário e escolar, ela vai construindo sua concepção de língua escrita, reconhecendo diferentes usos sociais da escrita, dos gêneros, suportes e portadores. Frente a isso, o documento ressalta na Educação Infantil, para este processo de inserção numa cultura escrita deve-se considerar o que as crianças sabem e quais as curiosidades que manifestam. As experiências com as atividades de leitura literária mostram uma possibilidade de estímulo à imaginação e à ampliação do conhecimento de mundo, visto que "o contato com histórias, contos, fábulas, poemas, cordéis etc. propicia a familiaridade com livros, com diferentes gêneros literários, a diferenciação entre ilustrações e escrita, a aprendizagem da direção da escrita e as formas corretas de manipulação de livros". (BRASIL, 2017, p. 4I)

Sendo a leitura uma ação de construção efetiva, seja do significado estabelecido pelo texto ou do sentido criado pelas particularidades individuais do leitor, a sua prática é fundamental para o desenvolvimento cognitivo e discursivo. Segundo Paulino (2001, p. 22) "Ao ler, um indivíduo ativa seu lugar social, suas vivências, sua biblioteca interna, suas relações com o outro, os valores de sua comunidade".

É fundamental que o professor alfabetizador desperte no educando o interesse e aptidão pela apreciação de obras literárias, favorecendo a leitura através de estratégias e condições para o crescimento individual do leitor. É necessário que a leitura permita uma relação entre educadores e educando, pois a cada dia o mundo da alfabetização nos desafia, a se posicionar de maneira crítica e transformadora (CORDEIRO \& MOURA, 2020). 


\section{CONCLUSÃO}

A importância da leitura está diretamente relacionada ao desenvolvimento da criança desde o início da educação infantil, sendo importante ressaltar que ela deve fazer parte do cotidiano infantil e também existir nos diversos ambientes escolares, por meio de cartazes, figuras representativas de expressões, cantinho de leitura na sala de aula e espaços de leitura em outras áreas da escola.

Desde muito cedo, as crianças expostas à linguagem escrita, desenvolvem imaginação, concentração, memória e atenção, sem falar na aquisição de um novo vocabulário e na descoberta do mundo por meio dos sentimentos e emoções transmitidos pelos livros.

Este trabalho apresenta os importantes fatores que motivam a formação de excelentes leitores, que utilização da leitura no dia-a-dia, desempenha um papel fundamental na sociedade e ampliem continuamente seus horizontes de conhecimento.

É necessário e importante que as crianças comecem a ler na educação infantil. Temos consciência da importância do papel de intermediário dos professores, pois têm a responsabilidade de proporcionar aos alunos um espaço de leitura adequado e de transformar esses espaços em um ambiente agradável de aprendizagem. As histórias são essenciais para o ensino da leitura e o treinamento de crianças, pois atraem leitores de todas as idades.

\section{REFERÊNCIAS BIBLIOGRÁFICAS}

ALBUQUERQUE, Joelma Cavalcante de. Considerações sobre o trabalho pedagógico com a literatura infantil na pré-escola / Joelma Cavalcante de Albuquerque. - João Pessoa: UFPB, 2013. 45f.; il. Disponível em https://repositorio.ufpb.br. Acesso em 23/o6/2021.

BRASIL. Ministério da Educação e do Desporto. Base Nacional Comum Curricular. Brasília: MEC/SEF, 2017.

CAMARGO, Maria Aparecida Santana; SILVA, Mari Jaqueline Pinto. A literatura infantil como um recurso pedagógico indispensável. Revista ESPACIOS. Vol. 4I (№ o9) Ano 2020. Disponível em 〈https://www.revistaespacios.com/a20v4Ino9/a20v4Ino9pi3.pdf〉. Acesso em 23/o6/202I.

COELHO, Nelly Novaes. Literatura Infantil: teoria, análise, didática. São Paulo: Moderna, 2000. 
CORDEIRO, Lívia Barreto; MOURA, Luciana Teles. Leitura deleite como forma de estímulo em turmas do $2^{\circ}$ ano do Ensino Fundamental. Kiri-kerê: Pesquisa em Ensino, n.9, dez. 2020. Disponível em 〈https://periodicos.ufes.br/kirikere/article/view/328or/22675> Acesso em 23/o6/2021.

FERREIRA, Laís Costa; OLIVEIRA, Rosemary Lapa de. A contação de histórias como prática educativa. Revista Digital dos Programas de Pós-Graduação do Departamento de Letras e Artes da UEFS Feira de Santana, v. 21, n. 2, p. 66-75, maio-agosto de 2020. Disponível em http://periodicos.uefs.br/index.php/acordasletras/article/view/66/pdf. Acesso em 23/o6/2021

FORTESKI, Elaine. et al. Prazer pela leitura: incentivo e o papel do professor. Ágora: R. Divulg. Cient., v. 18, n. 2, p. 120-127, dez. 20II (ISSN 2237-9010). Disponível em: $\langle$ https://www.periodicos.unc.br〉. Acesso em: 23/o6/2021.

FRANCISCO, Fernanda Ruiz. A contação de histórias no Ensino de Ciências: um recurso didático / Fernanda Ruiz Francisco, 2015. 75 f: il. Disponível em https://repositorio.unesp.br. Acesso em 25/o6/2021.

FREIRE, Paulo. A importância do ato de ler [livro eletrônico]: em três artigos que se completam / Paulo Freire. I. ed. São Paulo: Cortez, 2017. (Coleção questões da nossa época; v. 22).

GARCIA, Sílvia Craveiro Gusmão. Leitura e contação de histórias: um exercício imaginário. São Paulo: UNIRP, 2010. Disponível em <www.alb.com.br/cole3642.pdf >Acesso em: 28/o9/2011.

GENEROSO, Ariana da Silva Fagundes O Texto Literário Infantil em Contextos de Alfabetização: um olhar para as práticas de formação inicial do leitor. Dissertação (Mestrado) - Pontifícia Universidade Católica do Rio Grande do Sul, Faculdade de Educação, Programa de Pós-Graduação em Educação, Porto Alegre, RS, 2014. Disponível em <https://repositorio.pucrs.br〉. Acesso em 23/o6/2021.

GOULEMOT, J. M. Da leitura como produção de sentido. In: CHARTIER, R. Práticas de leitura. Tradução Cristiane Nascimento. São Paulo: Estação Liberdade, 1996.

LANDIM, Márcia Regina Melchior; FLÔRES, Onici Claro. Aprendizagem da leitura: preditores emergentes na pré-escola. Revista Digital dos Programas de Pós-Graduação do Departamento de Letras e Artes da UEFS Feira de Santana, v. 19, n. 3, p. 27-37, 2018. Disponível em https://www.researchgate.net. Acesso em 23/o6/202I.

JARDIM, Mora. Iniciação a Literatura: Questões norteadoras para a formação do professor io, Porto Alegre,19994.

MAGNANI, Maria do Rosário M. Leitura, literatura e escola: subsídios para a reflexão sobre a formação do gosto. São Paulo: Martins Fontes, 1989. 
MARTINS, Maria Helena. O que é Leitura. São Paulo: Brasiliense, 2003. (Coleção primeiros passos; 74). Disponível em: <http://letraslite.blogspot.com/2013/o6/resenha-oque-e-leitura-de-maria-helena.html $>$ Acesso em: 23/o6/2021.

MARTINS, Maria Helena. O que é leitura. 19. ed. São Paulo: Brasiliense, 1994.

NÓBREGA, Paulo Vinícius Ávila; MANGUEIRA, José Vilian. (orgs.) Estudos sobre línguas e literaturas na educação básica. São Paulo: Pimenta Cultural, 2021. 565p.

NUNES, Izonete. et al. A Importância do incentivo à leitura na visão dos professores da Escola Walt Disney. REFAF 2020 - Revista Eletrônica Multidisciplinar da Faculdade de Alta Floresta - ISSN: 2238-5479. Disponível em $\langle$ http://refaf.com.br/index.php/refaf/article/view/53/html $>$. Acesso em 23/o6/2021.

PAULINO, G. et al. Tipos de textos, modos de leitura. Goiânia: Formato, 20or.

PRADO, Maria Dinorah Luz do. O livro infantil e a formação do leitor. Petrópolis: Vozes, 1996.

RODRIGUES, Jaqueline Lira. Contação de histórias na educação infantil [manuscrito]: uma experiência na prática docente. Jaqueline Lira Rodrigues. - 20II. 46f. : il. color. Disponível em <https://www.educaretransformar.net.br>. Acesso em 25/o6/202I.

SILVA, Aline Luiza da. Trajetória da literatura infantil: da origem histórica e do conceito mercadológico ao caráter pedagógico na atualidade. REGRAD - Revista Eletrônica de Graduação do UNIVEM \| v. 2 - n. 2 - jul/dez - 2009. Disponível em<https://revista.univem.edu.br > Acesso em 25/06/2021.

SORRENTI, Neusa, A hora e a vez da literatura: Revista presença pedagógica. Belo Horizonte: Ed. Dimensão, 1995 . 